\title{
Ion-Pair Chromatographic Separation of Nomifensine Maleate Enantiomers
}

\author{
Tsuyoshi Tsujiyama*, Misao Tsuchiya**, Yozo HamaChi*, Takeo KURIKI*, \\ Takehiko FUKUNAGA** and Nobuo SUzUkI*
}

* Pharma Research Laboratoratories, Hoechst Japan Ltd., Minamidai, Kawagoe, Saitama 350, Japan

**Pharma Quality Control Deparment, Nippon Hoechst K. K., Minamidai, Kawagoe, Saitama 350, Japan

\begin{abstract}
An ion-pair chromatographic method for separation of enantiomers of nomifensine maleate was established. Chiral separation was achieved by chromatography for $N$-trifluoroacetylated nomifensine maleate enantiomers on Supherisorb Silica $5 \mu \mathrm{m}$, a normal phase column, using a mixture of chloroform, methanol and water (100:3:0.15) containing a chiral counter ion, $(+)$-camphor-10-sulfonic acid $\left(2 \times 10^{-3} \mathrm{~mol}^{-1}\right)$ as the mobile phase. The standard curve obtained was straight line passing through the orgin; this extended from $25 \mathrm{ng}$ to $25 \mu \mathrm{g}$ of the injected material. The results suggested that the proposed method is simple and rapid enough to be applied for the purity test of nomifensine maleate enantiomers.
\end{abstract}

Keywords Nomifensine maleate, optical resolution, ion-pair chromatography, optical purity, $(+)$-camphor-10sulfonic acid.

A number of pharmaceutical drugs have asymmetric carbon atoms in the molecules. The optical forms, $d$ and $l$, of these atoms result in different pharmacokinetic parameters for absorption, metabolism and excretion. ${ }^{1,2}$ However, most of those drugs have been used as racemates because of difficulties in optical resolution and asymmetric synthesis. To examine the differences in the in vivo kinetics and pharmacological effects among enantiomeric drugs, establishment of a method to separate the enantiomers is a prerequisite.

Nomifensine maleate (8-amino-1,2,3,4-tetrahydro-2methyl-4-phenylisoquinoline maleate) is a novel antidepressant. It has an isoquinoline structure, which is different from the three-membered ring system found in conventional antidepressants. Nomifensine maleate has an asymmetric carbon atom at the 4-position. The $d$ form is much more potent than the $l$-form in the synaptosomal catecholamine uptake, an index for evaluation of an antidepressive effect. ${ }^{3}$

We have applied high performance liquid chromatography (HPLC) to measure the optical purity of nomifensine maleate enantiomers used for in vivo kinetic study or for evaluation of pharmacological effects.

Conventional methods for separation of enantiomers by HPLC can be classified into two: 1) the direct method, in which enantiomers are chromatographed with chiral stationary or mobile phases, such as a mobile phase containing amino acid-copper sulfate ${ }^{4,5}$, chiral counter ion $^{6,7}$ or $\beta$-cyclodextrin ${ }^{8}$, a stationary phase combined with crown ether ${ }^{9}, \pi$-electron receptor or hydrogen bonding reagent ${ }^{10,11}$ or with a $\mathrm{Cu}$ (II)containing mobile phase with an L-amino acid-bonded stationary phase ${ }^{12}$ and 2) the indirect method in which the diastereomers formed from enantiomers with a chiral reagent are chromatographed with an ordinary stationary phase and mobile phase using optically active isocyanate ${ }^{13,14}$, amino acid derivatives ${ }^{15}$ and carboxylic acid ${ }^{16}$ as a chiral agent. The indirect method has a wider applicable range than the direct method and is suitable to analyses with high sensitivity. However, the indirect method has disadvantages in that optically pure reagents are required for the formation of diastereoisomers. We tried to derivatize nomifensine maleate with various chiral reagents, but could not separate its enantiomers. This difficulty may be ascribable to the distance between the asymmetric carbon atom at the 4-position and the amino group at the 8-position. Optical resolution of nomifensine maleate enantiomers could not be attained by use of chiral stationary phases. So we tried to establish a rapid and simple, direct method using a chiral mobile phase containing (+)-camphor-10-sulfonic acid ${ }^{6}$ as counter ion and a column of ordinary silica.

\section{Experimental}

\section{Apparatus}

The pieces of apparatus used were a JASCO (Tokyo, 
Japan) high performance liquid chromatograph (model BIP) equipped with a detector (model UVIDEC 100IV) and a JASCO polarimeter (model DIP-181).

\section{Materials}

Nomifensine maleate (racemate) was obtained from Hoechst AG (FRG). Needed amounts of (+)-camphor10-sulfonic acid and trifluoroacetic anhydride (TFAA) were purchased from Tokyo Kasei (Tokyo, Japan). Pentafluoropropionic anhydride (PFPA) and heptafluorobutyric anhydride (HFBA) were purchased from Gas-Chro Kogyo (Tokyo, Japan) and Nakarai Chemicals (Kyoto, Japan), respectively. All solvents for HPLC were products of E. Merck (Darmstadt, FRG). N( $p$-Nitrobenzoly)-L-glutamic acid was prepared by the usual method. ${ }^{17} \mathrm{~N}$-Benzenesulfonyl-L-glutamic acid was synthesized as described in the next paragraph. Other reagents used were of analytical grade.

\section{Synthesis of N-benzenesulfonyl-L-glutamic acid}

A $73.5 \mathrm{~g}$ portion of L-glutamic acid was dissolved in $500 \mathrm{ml}$ of $1 \mathrm{~mol} \mathrm{l}^{-1} \mathrm{HCl}$, and $84.5 \mathrm{~g}$ of calcium oxide was added. Then, $90.0 \mathrm{~g}$ of benzenesulfonyl chloride was slowly added dropwise under reflux; this reflux was continued for about $2 \mathrm{~h}$. After cooling, the mixture was acidified with conc. $\mathrm{HCl}$, then extracted with four portions of ethyl acetate. The organic phase was treated with anhydrous $\mathrm{Na}_{2} \mathrm{SO}_{4}$ and activated charcoal. $\mathrm{Re}$ moval of ethyl acetate gave $84 \mathrm{~g}$ of the title compound (yield: 59\%). mp: $135-136^{\circ} \mathrm{C}$.

\section{Resolution of racemic nomifensine maleate by fractional crystallization}

To $35.4 \mathrm{~g}$ of nomifensine maleate (racemate), $350 \mathrm{ml}$ of $1 \mathrm{~mol} \mathrm{l}^{-1} \mathrm{NaOH}$ was added. After extraction with $500 \mathrm{ml}$ of ether, the ether layer was washed with water. After the ether was evaporated, $350 \mathrm{ml}$ of $N$-benzenesulfonyl-L-glutamic acid aqueous solution $(28.7 \mathrm{~g}-350 \mathrm{ml})$ and $200 \mathrm{ml}$ of ethanol were added to the residue, and the mixture was stirred at room temperature.

The precipitate was collected by filtration and recrystallized from water. Then, $150 \mathrm{ml}$ of $1 \mathrm{~mol} \mathrm{l}^{-1}$ $\mathrm{NaOH}$ was added to the crystals and the mixture was extracted with $300 \mathrm{ml}$ of ether. After the ether was evaporated, maleic acid-ethanol solution was added to the residue to produce the corresponding salt. Recrystallization from ethanol-water mixture $(2: 3)$ gave $d$-nomifensine maleate.

Two hundred milliliters of $1 \mathrm{~mol} \mathrm{l}^{-1} \mathrm{NaOH}$ was added to the filtrate, and the mixture was extracted with $300 \mathrm{ml}$ of ether. After the ether was evaporated, an ethanol solution containing $29.6 \mathrm{~g}$ of $N$-(p-nitrobenzoyl)-L-glutamic acid was added and the mixture was refluxed. After cooling, insoluble crystals were collected by filtration and recrystallized from water. After addition of $150 \mathrm{ml}$ of $1 \mathrm{moll}^{-1} \mathrm{NaOH}$, the crystalline precipitate was extracted with $300 \mathrm{ml}$ of ether and the ether was evaporated. Maleic acid-ethanol solution was added to the residue to produce the corresponding salt, which was recrystalized from ethanol-water mixture $(2: 3)$ to give $l$-nomifensine maleate.

\section{HPLC condition}

Column, Supherisorb Silica $5 \mu \mathrm{m}(250 \mathrm{~mm} \times 3.6 \mathrm{~mm}$ i.d., Harwell, England); mobile phase, a mixture of chloroform, methanol and water $(100: 3: 0.15)$ containing (+)-camphor-10-sulfonic acid $\left(2 \times 10^{-3} \mathrm{~mol} \mathrm{l}^{-1}\right)$; flow rate, $1 \mathrm{ml} / \mathrm{min}$; and detection, UV $254 \mathrm{~nm}$.

\section{Preparation of sample solutions for HPLC}

To $8 \mathrm{mg}$ of nomifensine maleate, $0.2 \mathrm{ml}$ of an acylating reagent (TFAA, PFPA or HFBA) was added and the mixture was stirred at room temperature for $10 \mathrm{~min}$. Excess reagent was evaporated off under nitrogen gas flow at $40^{\circ} \mathrm{C}$. The residue was dissolved in $2 \mathrm{ml}$ of the mobile phase and $5 \mu \mathrm{l}$ of the solution was subjected to HPLC.

Table 1 Effect of organic solvents in mobile phase on optical resolution of $\mathrm{N}$-trifluoroacetyl-nomifensine maleate enantiomers

\begin{tabular}{|c|c|c|c|c|c|}
\hline \multirow{2}{*}{ Main solvent } & \multirow{2}{*}{\multicolumn{2}{|c|}{ Polar solvent, $\%$}} & \multicolumn{2}{|c|}{$k^{\prime}$} & \multirow{2}{*}{$\boldsymbol{R}$} \\
\hline & & & (d) & $(l)$ & \\
\hline \multirow[t]{6}{*}{ Chloroform } & Methanol & (4) & 4.2 & 4.7 & 1.4 \\
\hline & Ethanol & (7) & 3.7 & 4.1 & 1.1 \\
\hline & Isopropanol & (13) & 3.9 & 4.5 & 0.8 \\
\hline & 1-Propanol & (13) & 3.9 & 4.5 & 0.7 \\
\hline & Acetonitrile & (10) & $>40$ & $>40$ & - \\
\hline & Tetrahydrofu & (50) & $>40$ & $>40$ & - \\
\hline \multirow[t]{4}{*}{ Dichloromethane } & Methanol & (4) & 4.5 & 4.8 & 1.0 \\
\hline & Ethanol & (7) & 3.2 & 3.4 & 0.9 \\
\hline & Isopropanol & (13) & 2.6 & 2.9 & - \\
\hline & 1-Propanol & (13) & 2.8 & 3.0 & - \\
\hline Ethyl acetate & Methanol & (4) & 6.3 & 6.3 & - \\
\hline
\end{tabular}

- , not calculated. 


\section{Results and Discussion}

\section{Organic solvent in mobile phase}

The chromatographic separation of $\mathrm{N}$-trifluoroacetylnomifensine maleate enantiomers with various mobile phases is given in Table 1 . When ethyl acetate was used as the main solvent, the enantiomer peaks exhibited tailing and were not resolved. Chroloform separated the enantiomer peaks better than dichloromethane. $N$-Trifluoroacetyl-nomifeminsine maleate did not elute with chloroform containing acetonitrile or tetrahydrofuran as the polar solvent, while chloroform containing methanol gave the most complete separation.

\section{Acylating reagent and content of methanol in mobile phase}

The separation of TFAA-, PFPA- or HFBA-acylated nomifensine maleate enantiomers was examined by use of a chloroform-methanol series as the mobile phase
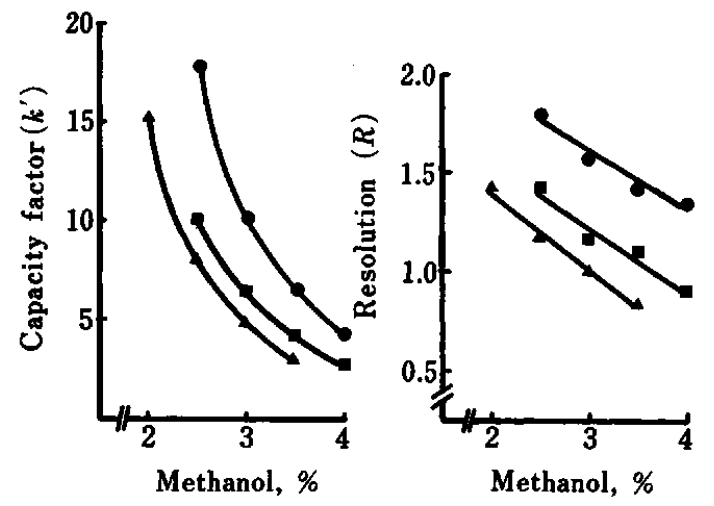

Fig. 1 Effect of methanol content in mobile phase on capacity factor of the first eluate and on resolution of enantiomers. - $N$-trifluoroacetyl-nomifensine maleate; $\square, N$-pentafluoropropionyl-nomifensine maleate; $\Delta, N$-heptafluorobutyryl-nomifensine maleate; mobile phase, chloroformmethanol series containing $(+)$-camphor-10-sulfonic acid $\left(2 \times 10^{-3} \mathrm{~mol} \mathrm{l}^{-1}\right)$.

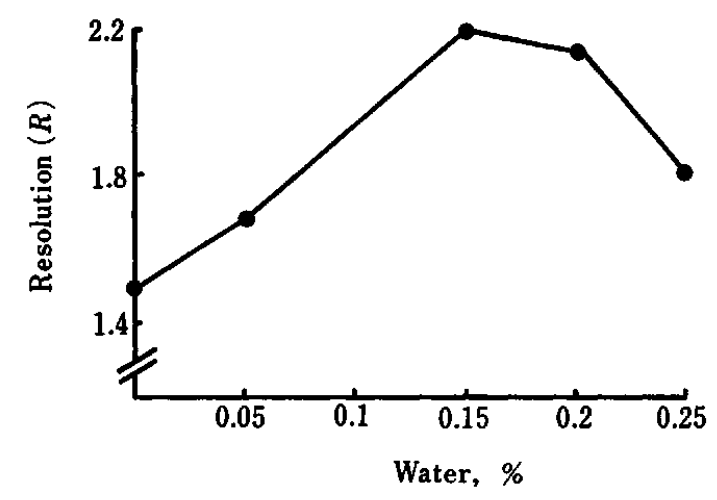

Fig. 2 Effect of water content in mobile phase on resolution of $\mathrm{N}$-trifluoroacetyl-nomifensine maleate enantiomers.
(Fig. 1).

As the methanol content increased, nomifensine maleate enantiomers acylated with each of the 3 acylating reagents exhibited smaller and smaller values of the capacity factor $\left(k^{\prime}\right)$, i.e., retention time, and of the resolution $(R)$. N-Trifluoroacetyl-nomifensine maleate enantiomers could not be separated successfully at any of the methanol contents used.

The methanol content was fixed at $3 \%$ so that the analysis might terminate within $20 \mathrm{~min}$.

\section{Effect of water in mobile phase on resolution}

The proposed method is based upon the optical resolution of diastereometric ion pairs formed from $N$ trifluoroacetyl-nomifensine maleate enantiomers with (+)-camphor-10-sulfonic acid. The effect of water in the mobile phase on the optical resolution was examined (Fig. 2).

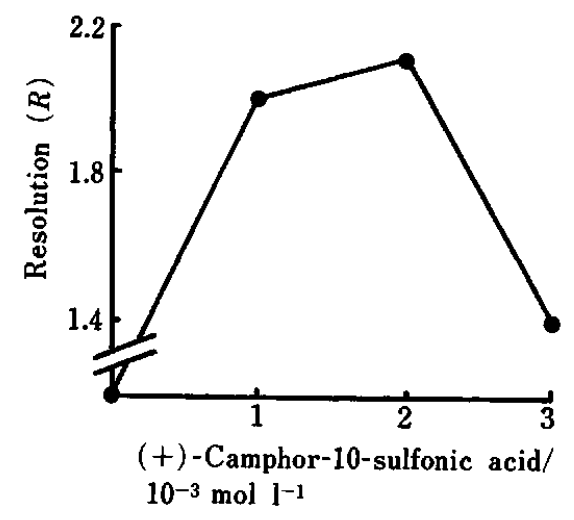

Fig. 3 Effect of (+)-camphor-10-sulfonic acid content on resolution of $N$-trifluoroacetyl-nomifensine maleate enantiomers.

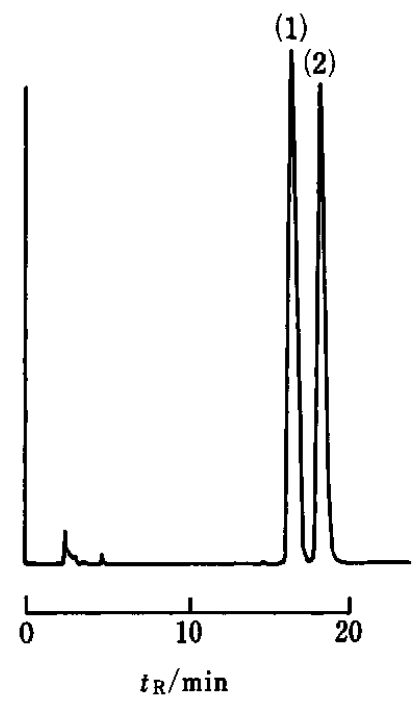

Fig. 4 Separation of $N$-trifluoroacetyl-nomifensine maleate enantiomers. 1: $N$-trifluoroacetyl- $d$-nomifensine maleate $(10 \mu \mathrm{g})$. 2: $N$-trifluoroacetyl- $l$-nomifensine maleate $(10 \mu \mathrm{g})$. 
Table 2 Optical purity of nomifensine maleate

\begin{tabular}{|c|c|c|c|c|}
\hline & & $d$-Form, \% & $l$-Form, $\%$ & $\begin{array}{c}\text { Optical } \\
\text { rotation }\end{array}$ \\
\hline Racemate & & 50.0 & 50.0 & 0.0 \\
\hline $\mathbf{A}$ & $\begin{array}{l}d \\
l\end{array}$ & $\begin{array}{r}100.0 \\
0.6\end{array}$ & $\begin{array}{r}0.0 \\
99.4\end{array}$ & $\begin{array}{l}+38.2 \\
-38.1\end{array}$ \\
\hline B & $\begin{array}{l}d \\
l\end{array}$ & $\begin{array}{r}96.0 \\
3.0\end{array}$ & $\begin{array}{r}4.0 \\
97.0\end{array}$ & $\begin{array}{l}+37.9 \\
-38.0\end{array}$ \\
\hline
\end{tabular}

A: recrystallization, 3 times.

B: recrystallization, once.

As the water content increased in the mobile phase, the resolution was raised; it reached a maximum at $0.15-2.0 \%$. The most suitable content of water was determined to be $0.15 \%$.

\section{Content of (+)-camphor-10-sulfonic acid}

Figure 3 shows the effect of the content of ( + camphor-10-sulfonic acid in the mobile phase on the optical resolution. A maximum resolution was obtained at $2 \times 10^{-3} \mathrm{~mol} \mathrm{l}^{-1}$ of (+)-camphor-10-sulfonic acid.

\section{Chromatogram and standard curve}

The chromatogram of $N$-trifluoroacetyl-nomifensine maleate enantiomers obtained by the present system is given in Fig. 4. The standard curves of $d$ - and $l$-forms were linear in the range $25 \mathrm{ng}-25 \mu \mathrm{g}$, passing through the origin.

\section{Practical application}

The optical purity of $d$ - and $l$-nomifensine maleate obtained by fractional crystallization with L-glutamic acid derivative was determined by the proposed HPLC system. As shown in Table 2, the optical purity could be measured more accurately by the proposed method than the method using optical rotation as parameter. The proposed system is applicable to the purity test for nomifensine maleate enantiomers.
The detection limit of nomifensine maleate enantiomer by this method was $25 \mathrm{ng}$ of the injected material. A further study is in progress on how to improve the proposed method for the detemination of trace nomifensine maleate enantiomers, for evalution of in vivo kinetics.

\section{References}

1. T. Walle and U. K. Walle, Res. Commun. Chem. Pathol. Pharmac., 23, 453 (1979).

2. M. J. Kreek, D. L. Hachey and P. D. Klein, Life Sci., 24, 925 (1979).

3. U. Schacht and M. Leven, Eur. J. Pharmacol., 98, 275 (1984).

4. L. R. Gelber and J. L. Neumeyer, J. Chromatogr., 257, 317 (1983).

5. S. Lam and A. Karmen, J. Chromatogr., 289, 339 (1984).

6. C. Pettersson and G. Schill, J. Chromatogr., 204, 179 (1981).

7. C. Pettersson and K. No, J. Chromatogr., 282, 671 (1983).

8. J. Debowski, D. Sybilska and J. Jurczak, J. Chromatogr., 237, 303 (1982).

9. G. D. Y. Sogah and D. J. Cram., J. Am. Chem. Soc., 101, 3035 (1979).

10. W. H. Pirkle, D. W. House and J. M. Finn, J. Chromatogr., 192, 143 (1980).

11. N. Öi, M. Nagase and T. Doi, J. Chromatogr., 257, 111 (1983).

12. N. Watanabe, J. Chromatogr., 260, 75 (1983).

13. J. A. Thompson, J. L. Holtzman, M. Tsuru, C. L. Lerman and J. L. Holtzman, J. Chromatogr., 238, 470 (1982).

14. T. Kinoshita, Y. Kasahara and N. Nimura, $J$. Chromatogr., 210, 77 (1981).

15. J. Hermansson, J. Chromatogr., 227, 113 (1982).

16. J. Goto, M. Hasegawa, S. Nakamura, K. Shimada and T. Nambara, J. Chromatogr., 152, 413 (1978).

17. S. Yoshida, K. Imai and S. Akagi, Yakugaku Zasshi, 69, 207 (1949).

(Received September 7, 1988) (Accepted March 27, 1989) 